\title{
Proceeding
}

6th INSHS International Christmas Sport Scientific Conference, 11-14 December 2011. International Network of Sport and

Health Science. Szombathely, Hungary

\section{4-18 Years old children attitudes, perception and motivation towards extra curricular physical activity and sport}

\author{
GENTI PANO , LUMTURI MARKOLA
}

Sport Sciences Research Institute, University of Sport of Tirana, Albania

\begin{abstract}
Pano G, Markola L. 14-18 Years old children attitudes, perception and motivation towards extra curricular physical activity and sport. J. Hum. Sport Exerc. Vol. 7, No. Proc1, pp. S51-S66, 2012. Factors affecting children's attitudes towards physical activity (PA) and physical education are complex and mediated by a range of variables such as social class, gender and race; body image and physical identity. 1062 highschool students (465 B and $597 \mathrm{G}$ ) 14-18 years old from 6 different Public high schools of Albania have fulfilled a questionnaire (EC DG EA), during January-June 2011 (only 6 questions were considered relevant). The aim was to reveal the 14.18 years old students attitudes and perception towards PA and Sport. Results show that: $14.21 \%$ e the subject's engage with PA and sport regularly despite their PA school program. 39\% engage with one kind of PA or sport during the week and also $36 \%$ are active rarely. B have a higher activation indicator (19.78\%) compared with $\mathrm{G}(9.88 \%)$. They are active mostly "for fun" with $35.87 \%$ and for "improving their physical image" with $33.08 \%$. Lack of free time $(53.57 \%)$ and the lack of sport facilities $(20.43 \%)$ are the main reasons why they don't engage with PA and sport despite their sport school program. There is a lack of information regarding the benefits of participation in PA and sport for this age. It is very necessary that the local or governmental authorities to create extracurricular PA programs and to offer more sport facilities and opportunities for this group-age. More studies focused on this group age are necessary in order to evaluate which is the most proper PA program for this group-age. Key words: PHYSICAL ACTIVITY, HIGH-SCHOOL STUDENTS, PERCEPTION, ATTITUDES.
\end{abstract}

\footnotetext{
Corresponding author. University of Sport of Tirana, Sport Sciences Research Institute, Albania.

E-mail: gentip2005@hotmail.com

6th INSHS International Christmas Sport Scientific Conference, 11-14 December 2011. International Network of Sport and Health Science. Szombathely, Hungary

JOURNAL OF HUMAN SPORT \& EXERCISE ISSN 1988-5202

(c) Faculty of Education. University of Alicante

doi:10.4100/jhse.2012.7.Proc1.07
} 


\section{INTRODUCTION}

Factors affecting children's attitudes towards physical activity and physical education are complex and mediated by a range of variables such as social class, gender and race (Azzarito et al., 2005); body image (Duncan al., 2004) and physical identity (Garrett, 2004). Studies have indicated that childhood and adolescence are important periods for adopting physically active lifestyle later in adulthood (Malina, 2001; Telama et al., 1997). Many researchers including Andersen et al., (2006), Biddleet al. (1998) and Strong et al., (2005) have detailed recommendations that children should participate in moderate physical activity (PA) at least 60 minutes per day. Many studies also report that young people's after school physical activity is rapidly diminishing (Telama \& Yang, 2000; Christodoulidiset al., 2001; Kamtsios \& Diggelidis, 2008). Identifying and understanding factors that associate with children's PA participation is critical to promoting current and lifelong physical activity participation of children (Sallis et al., 2000). According to Scanlan and Simons, (1992) enjoyment is an important factor in participation in sport that may lead to greater involvement in the activity. This clearly shows that physical activity is important to all individuals regardless of differences in gender. Abdullah and Omar Fauzee, (2002) posited that interpersonal relationship is an important element when engaging in physical activity. Children's motivation to participate in physical activity is influenced by their perception of the activity as being fun and worthwhile or boring or unpleasant (Fox, 1991; Martens, 1996). Sport club membership is often a result of the male oriented dominance of many sporting cultures (Flintoff, 2008). Silverman and Subramaniam, (1999) also reported that students tend to participate in PA they most get pleasure from. Gender differences have found that boys perceive themselves as more competent and report higher levels of enjoyment in physical activity (Carroll \& Loumidis, 2001; Soini, 2006). In the PE setting girls' perceived competence has been observed to decline with age, while for boys it remained stable (Van Wersch et al., 1992). The aim of this study was to reveal the high-school students attitudes and perception towards PA and Sport in the Albanians public schools.

\section{MATERIAL AND METHODS}

A total of 1062 high-school students (465 B and 597 G) 14-18 years old from 6 different Public high schools of Albania have fulfilled a questionnaire which was adapted for this study EC (DG EAC) (http://ec.europa.eu/public_opinion/index_en.htm), during January-June 2011 (only 6 questions were considered potentially relevant for this study). The aim of this study was to reveal the high-school students attitudes and perception towards PA and Sport in the Albanians public high-schools. We have compared the results between both sexes $(B \& G)$ and between the schools. We have compared the results between both sexes $(B \& G)$ and between the schools.

\section{RESULTS}

Question 1. How often do you exercise or play sport?

Possible responses: 5 times a week or more; 3 to 4 times a week; 1 to 2 times a week; 1 to 3 times a month; less often; never; don't know. 'Regularly' means the respondent exercises at least 5 times a week'; 'with some regularity' means 3 to 4 or 1 to 2 times a week; and 'seldom' means 1 to 3 times a month or less often. 


\section{Total \%}

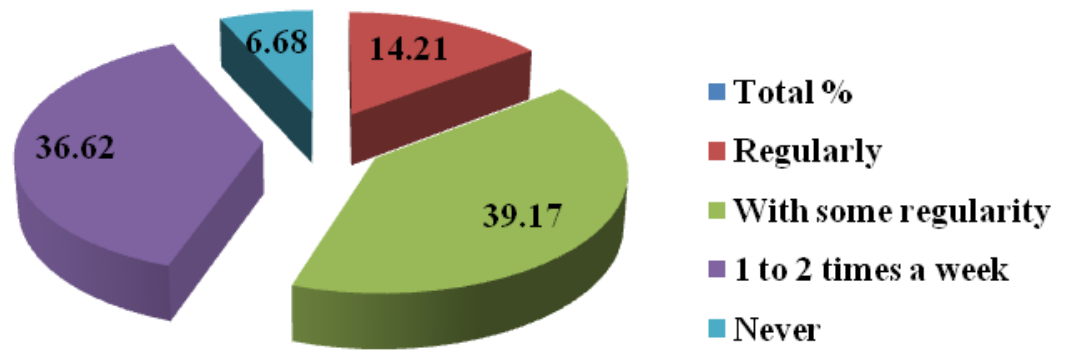

Figure 1. Question 1. Total results (B\&G).

Data's from 6 different public high-schools show that a considerable number of students exercise or playsport "regularly" $14.21 \%$ and "with some regularity" $39.17 \%$, which is a positive indicator and as consequence the alternative "never" has a low indicator only with $6.68 \%$ (Figure 1). But a very alarming fact is that the high-school student of sport club membership is very low (as we will see in question 4). A low percentage of the subjects (14.21\%) engage "Regularly" in PA while in the alternative with "some regularity" the results are good with $39.17 \%$ (Figure 1).

Between B and G results in the alternative "regularly" are; B with $19.78 \%$ has better results compared with the $\mathrm{G}$ with $9.88 \%$ (Figure 2). In the alternative "regularly" results show that B much are better than $\mathrm{G}$. In the other side in the alternative "with some regularity" G of MÇ with $15.07 \%$ and G of THG high-school with $7.03 \%$ have better results compared with the boys.

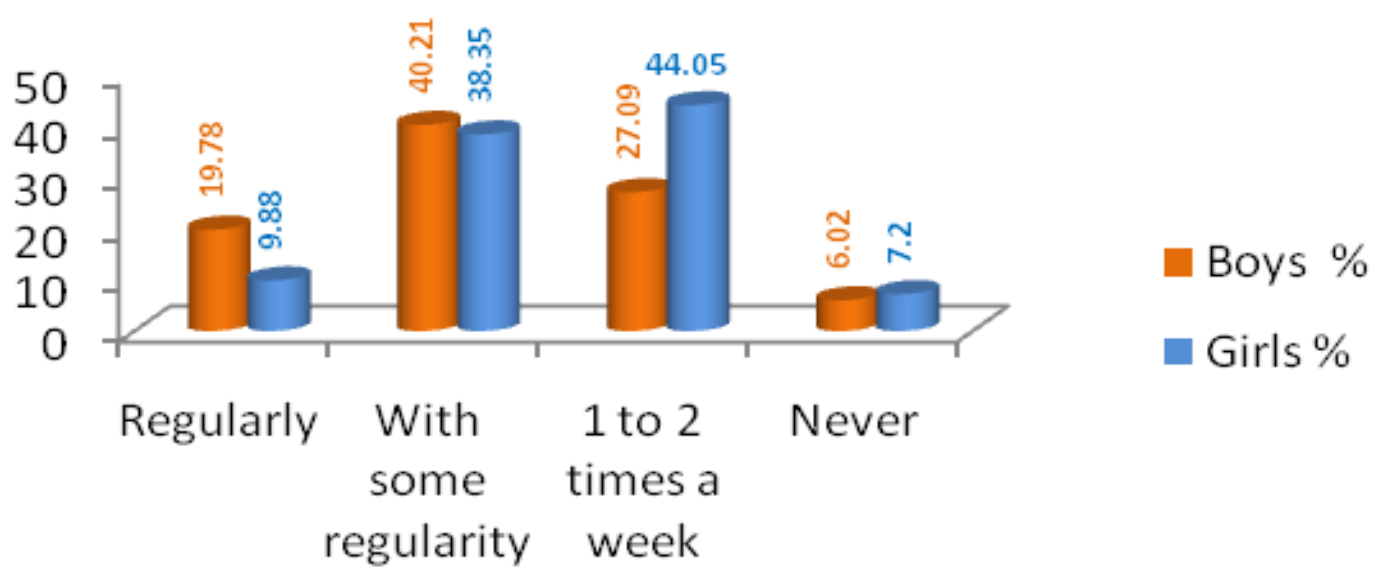

Figure 2. (Question 1) Differences between genders (B \& G). 
Meanwhile B of MÇ and PN high-schools have better results in the same alternative compared with $B$ of $P A R$ and GJK high-school. Differences between $B$ and $G$ in the alternative " 1 to 2 times a week is in favour of $\mathrm{G}$ with 44.05 compared with the B 27.09 (Table 1).

Table 1. (Question 1) Total schools result.

\begin{tabular}{lcccccc} 
& PAR \% & QS \% & PN \% & THG \% & MÇ \% & GJK \% \\
\hline Regularly & 1.5 & 1.48 & 2.45 & 2.35 & 6.71 & 1.06 \\
With some regularity & 3.86 & 6.35 & 5.12 & 6.31 & 14.73 & 2.83 \\
1 to 2 times a week & 3.01 & 9.35 & 3.35 & 8.86 & 9.05 & 1.85 \\
Never & 1.31 & 0.92 & 2.35 & 0.41 & 0.76 & 0.68 \\
\hline
\end{tabular}

Data analysis show strong differences between schools (Tab. 1). MÇ high-school has better indicators in most of the preferences. For example, in the alternative "regularly" this school is with $6.71 \%$ and the other schools are less than $2 \%$. Also PN with $2.45 \%$ and THG with $2.35 \%$ have very good indicators. In total data's the alternative" with some regularity" is very considerably competitive between schools. MÇ highschool with 14.73 have better indicators QS with $6.35 \%$ and THG with $6.31 \%$. Following this argument we can see that between genders exist interesting comparisons. Very low results are shown in GJK highschool with $1.09 \%$ and in the alternative "with some regularity" MÇ high-school with $14.73 \%$, PN highschool with $5.12 \%$, but in the alternative "1-2 times a week" QS high-school with 9.35\%, THG high-school with $8.86 \%$ have better results compared with the others.

Question 2

How often do you engage in a physical activity outside sport such as cycling or walking from a place to another, dancing, gardening...?' Possible responses: As question 1

\section{Total \%}
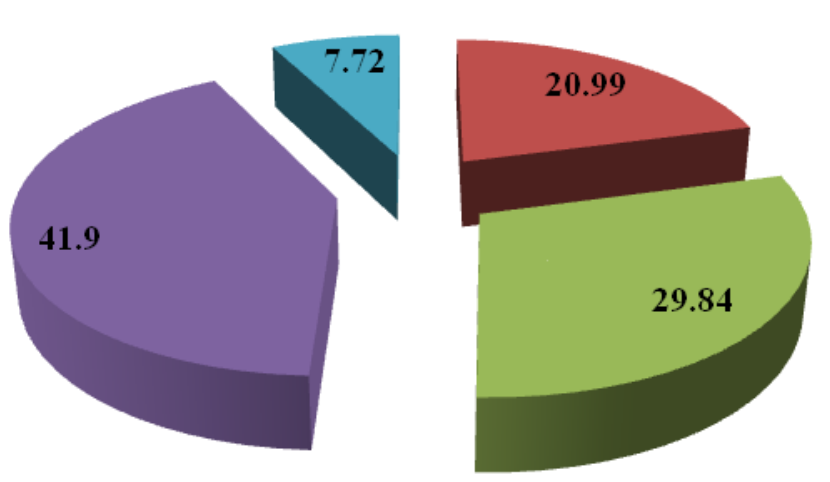

- Total \%

- Regularly

With some regularity

$\square 1$ to 2 times a week

- Never

Figure 3. (Question 2) Total results of non formal PA and sport. 
Question 2 data's result show that $29.84 \%$ the subjects (B \& G) have been engaged with one form of PA and sport once a week, but not in all the schools this marker is positive. In total all the high-school students have reported that they are physically active in extracurricular activities for example with: swimming, running, cycling and dancing. More than $20.99 \%$ report that they engage in PA and sport "Regularly" and $29.84 \%$ do some forms of PA "With some regularity" (Fig. 3). Nevertheless it is not a positive fact that a considerable number of subjects report that they are physically active rarely or once a week and $7.72 \%$ of them do not engage ever.

Gender differences

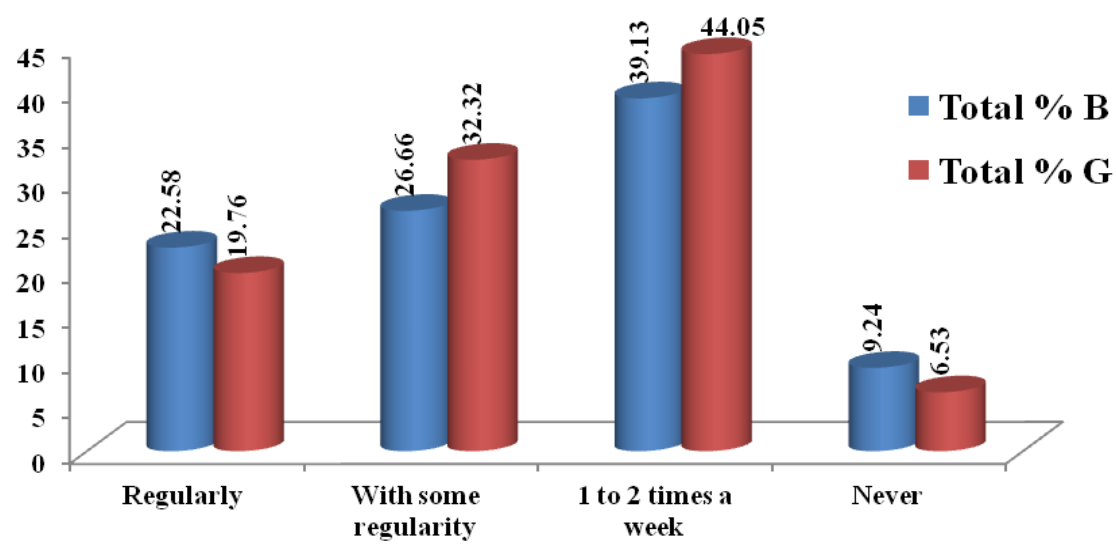

Figure 4. Gender Differences.

$G$ with $32.32 \%$ have a higher positive indicator than B with $26.66 \%$ in the alternative "with some regularity" which shows that $\mathrm{G}$ are more reasonable for their health and they tend to invest more time than $\mathrm{B}$. Also $\mathrm{G}$ have a higher value with $44.05 \%$ then B with $39.13 \%$ in the alternative "rarely". In general we can say that $\mathrm{G}$ and $\mathrm{B}$ have more less the same participation level in "rarely" alternative, which is a positive fact (Fig. 4).

Differences between schools

Table 2. (Question 2) Total schools result (B \& G).

\begin{tabular}{lcccccc}
\cline { 2 - 7 } & PAR \% & QS \% & PN \% & THG \% & MÇ \% & GJK \% \\
\hline Regularly & 1.73 & 1.27 & 2.61 & 1.56 & 13.27 & 1.32 \\
With some regularity & 11.21 & 3.82 & 3.61 & 4.08 & 10.12 & 2.61 \\
1 to 2 times a week & 3.59 & 9.04 & 5.78 & 10.39 & 8.81 & 3.32 \\
Never & - & 1.69 & 1.54 & 1.18 & 0.89 & 1.53 \\
\hline
\end{tabular}

In all high-school most of the students are engaged in non formal PA and the others are generally engaged in organized school curricular activities (Tab. 2). Students of MÇ in all responses show better results compared with the other schools. But also PAR, PN and THG high-schools have better results in the alterative "with some regularities" when PAR with $11.21 \%$ is represented better than the other schools even with MÇ is $10.12 \%$. 


\section{Question 3}

Where do you engage in sport or physical activity? Alternatives: In the park or outdoors; On the way to school; In a fitness centre; In a sport club; In a sports centre; At work; At school; Elsewhere; Don't know.

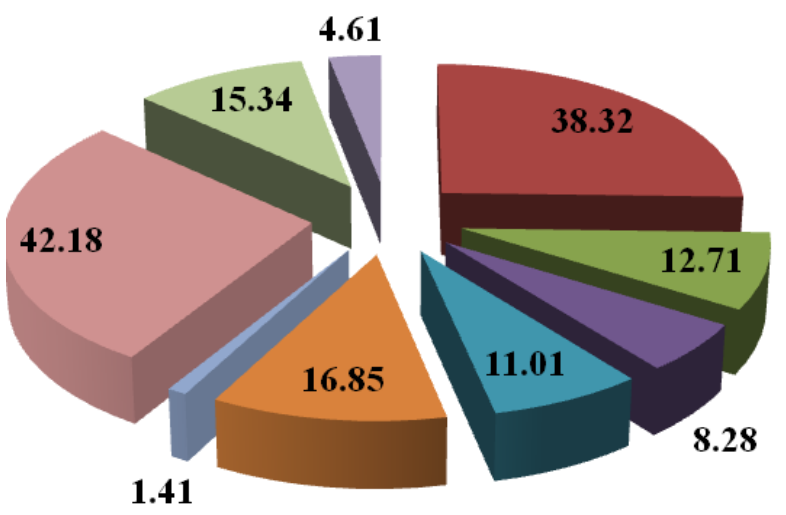

$$
\begin{aligned}
& \text { - Total } \% \\
& \text { - In the park or outdoors } \% \\
& \text { - On the way to school } \% \\
& \text { - In a fitness centre } \% \\
& \text { In a sport club } \% \\
& \text { In a sports centre } \% \\
& \text { At work } \% \\
& \text { At school } \% \\
& \text { Elsewhere } \% \\
& \text { Don't know } \%
\end{aligned}
$$

Figure 5. (Question 3) Total results of non formal PA and sport.

Total data's show that the preferences are very different. High-school students engage in PA and sport mostly in their schools (42.18\%) and in nature (38.32\%) followed by sport centers with $16.85 \%$. In the other side places that usually are mostly populated are not very preferred by high-school students (fitness center 8.28, sport clubs 11.01\%), (Figure 5).

Gender differences

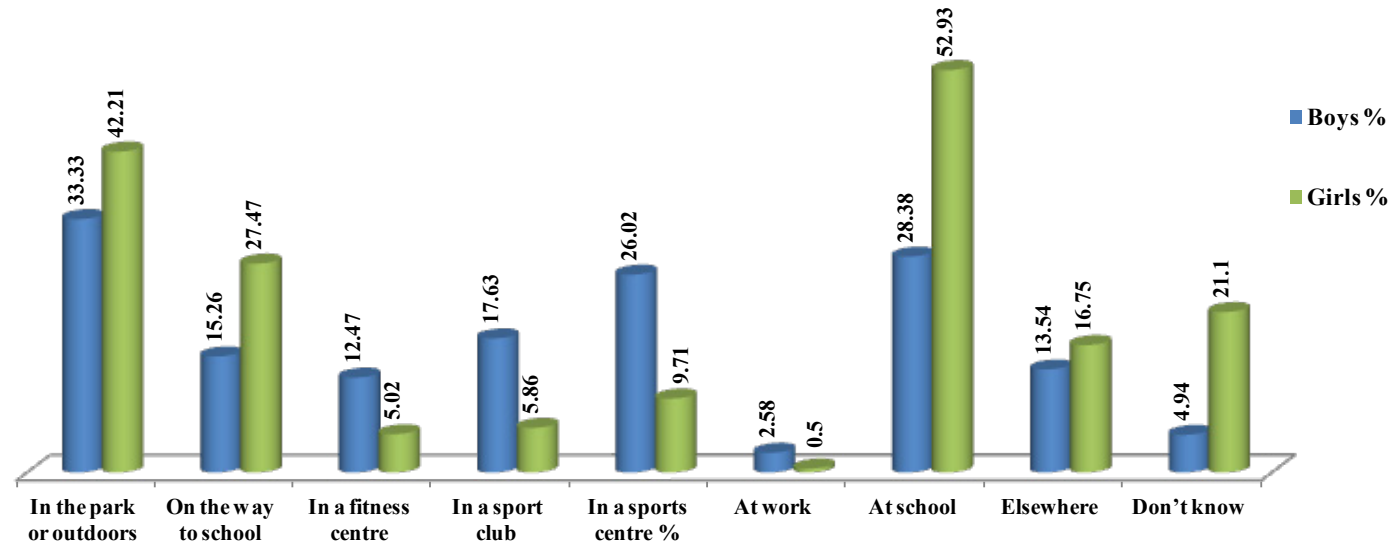

Figure 6. (Question 3) Differences between Genders (B \& G). 
Differences between $B$ and $G$ are very mixed. $33.33 \%$ of the $B$ prefers nature to be physical active, instead $52.63 \%$ of the $G$ prefers to engage in PA and sport at school. $27.47 \%$ of the $G$ has selected to be physically active alternatively going school (Figure 6).

Differences between schools

Table 3. (Question 3) Total schools result.

\begin{tabular}{rcccccc}
\hline Total (B\&G) & PAR & QS & PN & THG & MC & GJK \\
\hline In the park or outdoors \% & 3.16 & 5.5 & 3.12 & 8.36 & 14.85 & 11.56 \\
On the way to school \% & 0.81 & 2.59 & 4.22 & 3.07 & 8.12 & 1.84 \\
In a fitness centre \% & 0.75 & 1.02 & 1.01 & 1.59 & 2.65 & 0.54 \\
In a sport club \% & 2.07 & 1.8 & 2.61 & 0.85 & 3.48 & 1.18 \\
In a sports centre \% & 2.59 & 3.77 & 1.18 & 2.47 & 6.72 & 0.4 \\
At work \% & 0.34 & 0.83 & 0.33 & 0.33 & 0.86 & - \\
At school \% & 1.55 & 7.15 & 9.05 & 9.68 & 14.9 & 2.31 \\
Elsewhere \% & 0.75 & 4.13 & 2.61 & 2.84 & 4.03 & 1.79 \\
Don't know \% & 0.73 & 0.4 & 0.48 & 0.18 & 0.59 & 1.68 \\
\hline
\end{tabular}

Data's for the differences between schools show that the preferences are varied regarding the high-school children PA and sport engagement. $14.85 \%$ of MÇ school students prefer nature followed by THG students with 3.86\% and QS with 5.50\%. This form of engagement with PA and sport is less preferred in GJK highschool students with $1.56 \%$ and $P N$ with $3.12 \%$. G in general has the same preferences. $G$ of MÇ with $16.08 \%, G$ of QS with $6.02, G$ of THG with 11.41 prefer to be physically active in nature also $G$ of PN with $14.07 \%$, $\mathrm{G}$ of THG with 14.07 and $\mathrm{G}$ of MÇ with $19.93 \%$ prefer school facilities to be physically active (Table 3).

Question 4

Are you a member of any of the following clubs where you participate in sport or recreational physical activity? 


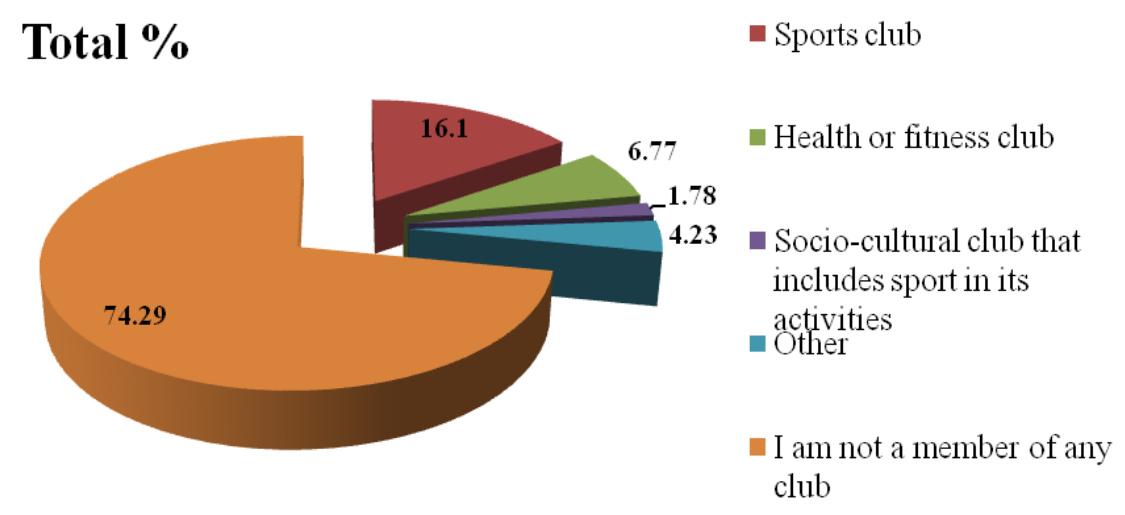

Figure 7. (Question 4) Total results of non formal PA and sport.

Data's results show that $74.29 \%$ of the subjects reveal that "I am not a member of any club" which means that mostly don't prefer to be part of organized sport facilities a very low indicator of inactivity. In the other side $16.1 \%$ are members of sports clubs, health or fitness clubs (Figure 7 ).

Gender differences

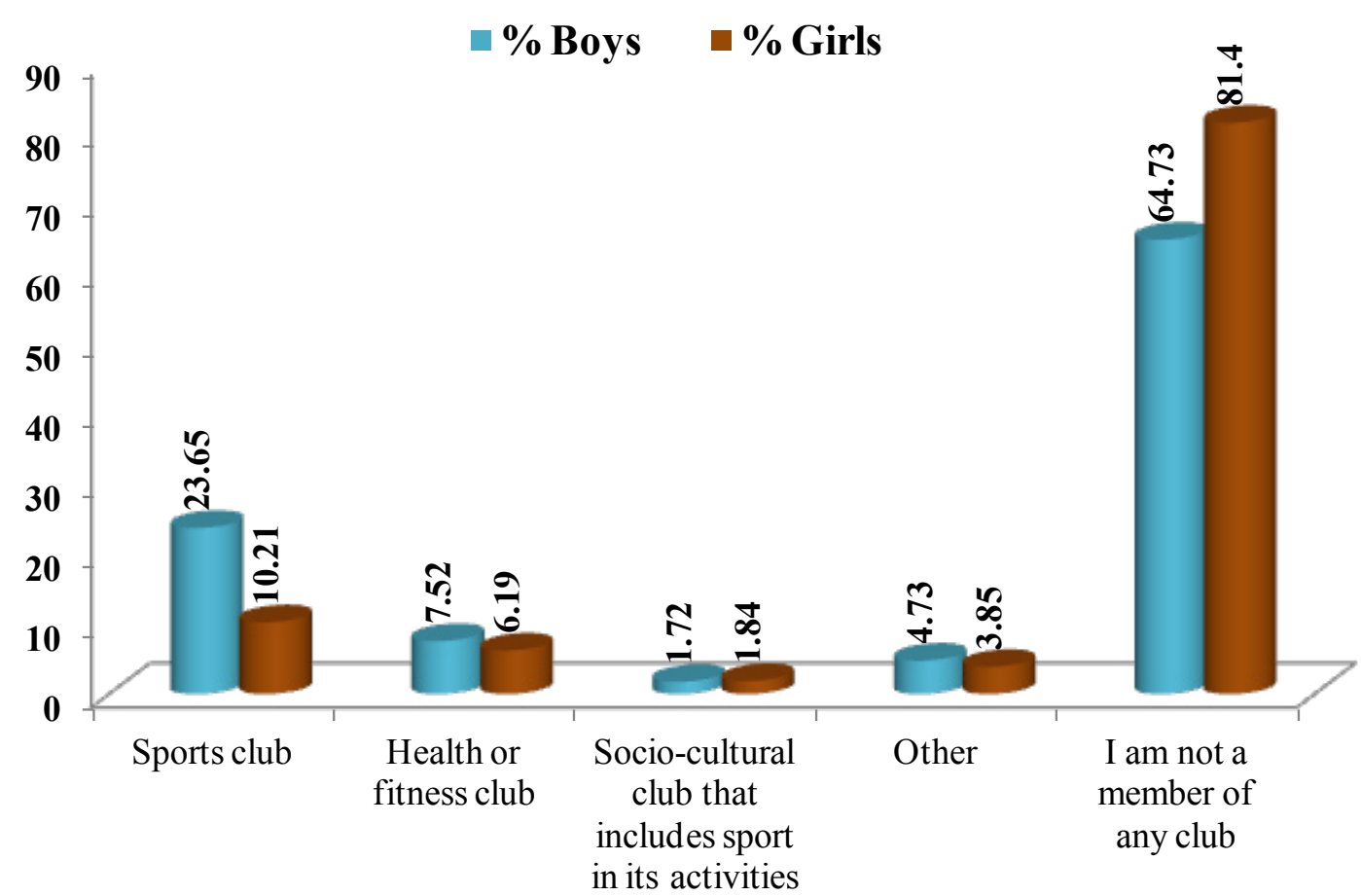

Figure 8. (Question 4) Genders differences.

More less $\mathrm{B}$ and $\mathrm{G}$ have the same $\%$ of PA and sport preferences regarding the places where they prefer to be physically active. Boys mostly prefer to be members of sport clubs with $23.65 \%$ compared with the $G$ $10.21 \%$. Generally $81.40 \%$ of the $G$ say that they are not members of any sport club in the other side $64.73 \%$ of the $B$ say the same thing (Figure 8 ). 
Differences between schools

Table 4. (Question 4) Total schools result.

\begin{tabular}{lcccccc}
\hline Possible responses & PAR & QS & PN & THG & MÇ & GJK \\
\hline Sports club & 1.88 & 2.16 & 4.28 & 1.03 & 5.16 & 1.72 \\
Health or fitness club & 0.56 & 2.82 & 1.4 & 0.94 & 0.62 & 0.68 \\
Socio-cultural club that includes sport in its activities & - & 1.43 & - & 0.21 & 0.58 & - \\
Other & 0.18 & 1.06 & 0.89 & 0.56 & 1.42 & 0.43 \\
I am not a member of any club & 6.4 & 11.86 & 11.32 & 10.32 & 25.16 & 6.02 \\
\hline
\end{tabular}

Result show that QS with 2.82\%, PN with 1.40\% prefer the fitness centers, while $4.28 \% \mathrm{PN}$ and $5.16 \%$ of MÇ have a higher participating on Sport club membership. The rapport between $B$ and $G$ is also different and only $10.21 \%$ of the $\mathrm{G}$ are member of sport clubs and boys are $23.65 \%$. G have a higher number of fitness club \%, QS with $3.68 \%$ and PN with $1.34 \%$ have a higher membership compared with other school, THG with $0.33 \%$, GJK with $0.16 \%$ and MÇ with $0.50 \%$ (Table 4).

\section{Question 5}

Why do you engage in sport or physical activity?

Possible responses (see Table 5):

One of the main factors that high-schools students prefer to engage in PA and sport is "for fun" with $35.87 \%$ followed by "to improve physical performance" with $33.08 \%$ and "to improve your health: with $28.78 \%$, reasons that are reasonable for this age. Also the possible response "to improve your self-esteem" with $26.17 \%$ and 'to improve your physical appearance' with $24.19 \%$, are indicators for their information for the values and benefits of PA and sport. 

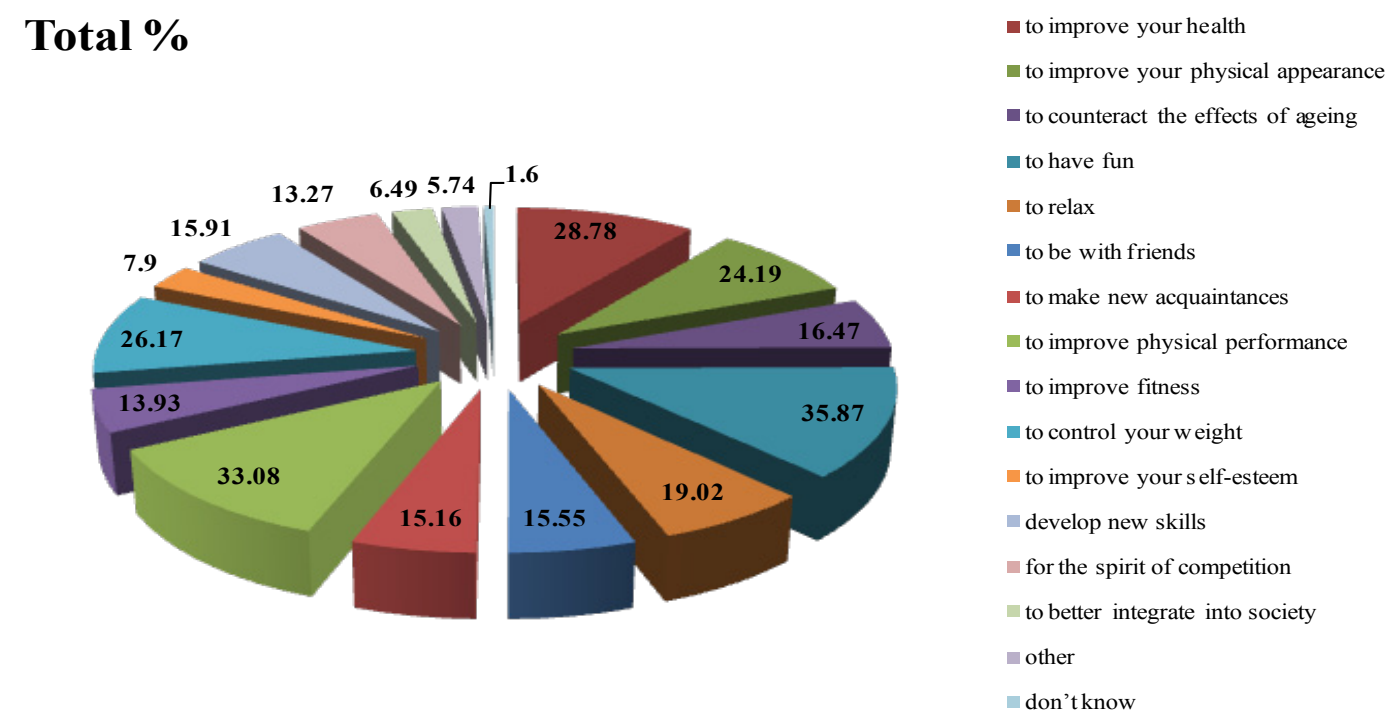

Figure 9. (Question 5) Total results of non formal PA and sport.

Also very interesting and also paradox for this age is the preference "to counteract the effects of ageing" with 16.47" This study reveals the general education level and culture related with their health and wellbeing which is also related with the school curriculum (Fig 9).

Gender differences

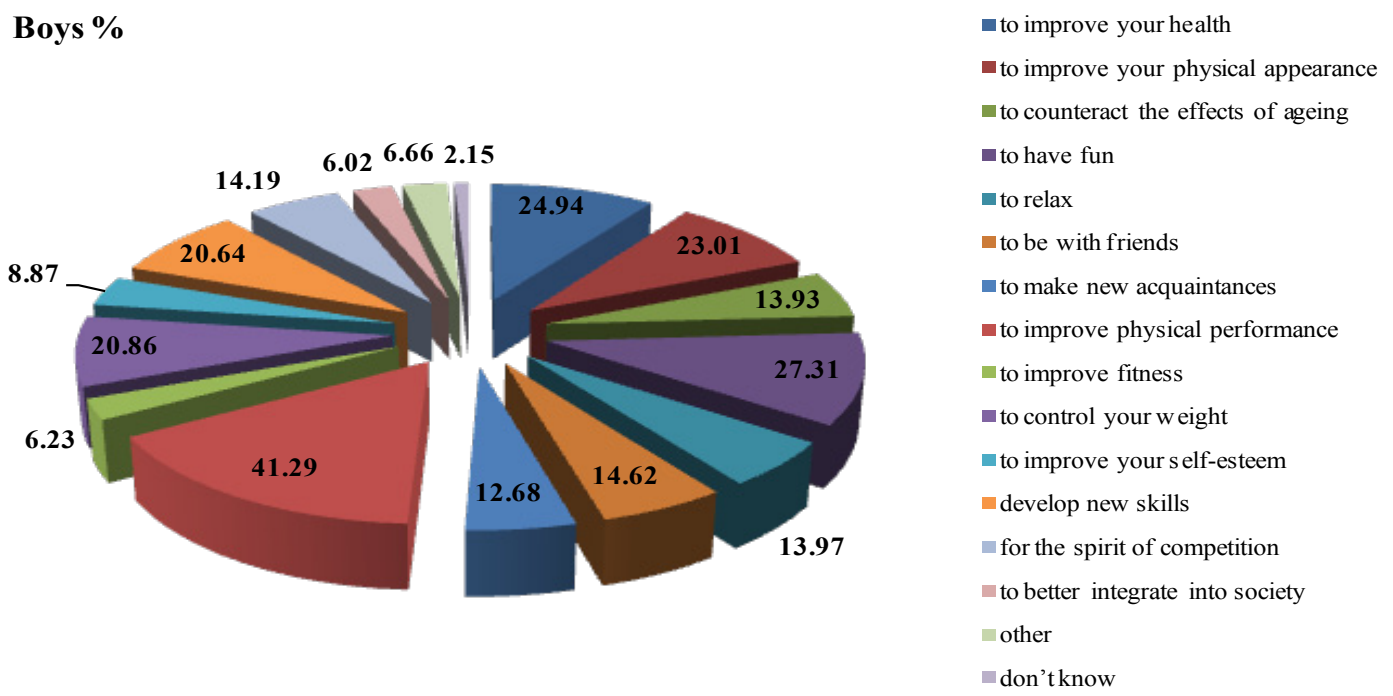

Figure 10. (Question 5) Total Boys (\%).

Results from gender differences show significant and interesting data's regarding the reasons that highschool students revel for why they engage with PA and sport. Girls are more motivated for the "fur fun" alternative with $42.54 \%$, "for health" with $31.49 \%$ and "to control the weight" with $30.31 \%$, which mean that $\mathrm{G}$ are more reasonable for health and body weight in the other side $\mathrm{B}$ are more motivated to "improve their physical appearance" with 41.29, "for fun" with $27.31 \%$ and "for health" with $24.94 \%$ (Fig. 10\&11). Fun as sociological element for being engaged is a reasonable reason that has been more evaluated from both genders. 
Girls \%

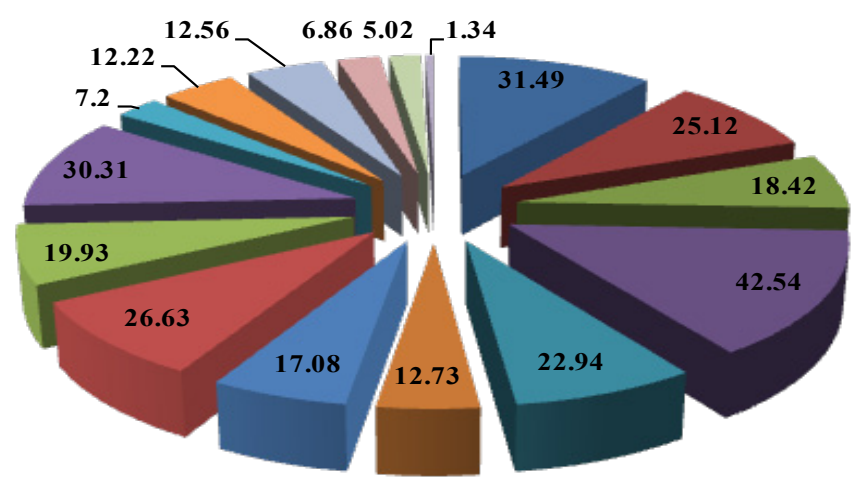

च to improve your health

n to improve your physical appearance

- to counteract the effects of ageing

to have fun

a to relax

- to be with friends

- to make new acquaintances

- to improve physical performance

to improve fitness

- to control your w eight

- to improve your s elf-esteem

adevelop new skills

for the spirit of competition

to better integrate into society

other

don't know

Figure 11. (Question 5) Total girls (\%).

Table 5. (Question 5) Total schools result.

\begin{tabular}{rcccccc}
\hline Possible responses & PAR & QS & PN & THG & MC & GJK \\
\hline to improve your health & 2.54 & 2.74 & 4.7 & 8 & 9.51 & 2.19 \\
to improve your physical appearance & 2.44 & 2.07 & 2.98 & 6.12 & 8.79 & 1.78 \\
to counteract the effects of ageing & 0.37 & 0.47 & 0.47 & 4.47 & 9.98 & 0.59 \\
to have fun & 3.48 & 9.96 & 2.98 & 8.9 & 11.29 & 1.41 \\
to relax & 1.69 & 3.48 & 2.98 & 5.17 & 4.8 & 0.81 \\
to be with friends & 0.65 & 4.8 & 2.68 & 1.82 & 2.98 & 0.75 \\
to make new acquaintances & 0.43 & 0.47 & 1.42 & 3.86 & 8 & 0.98 \\
to improve fitness & 0.75 & 0.56 & 0.37 & 1.95 & 10.12 & 0.18 \\
to control your weight & 1.6 & 4.82 & 4.23 & 8.47 & 5.39 & 1.69 \\
to improve physical performance & 3.1 & 7.25 & 3.1 & 6.12 & 8.9 & 2.71 \\
develop new skills & 2.16 & 3.02 & 1.57 & 2.82 & 3.98 & 1.49 \\
for the spirit of competition & 1.41 & 3.18 & 1.98 & 1.81 & 3.86 & 0.75 \\
to better integrate into society & 0.47 & 1.28 & 0.75 & 1.48 & 2.19 & 0.85 \\
Other & 0.47 & 1.38 & 1.69 & 0.98 & 0.98 & 0.31 \\
don't know & 0.09 & 0.16 & 0.75 & 0.08 & - & 0.75 \\
\hline & & & & & &
\end{tabular}




\section{Differences between schools}

In general high-students describe health as one of the most important factors influence them to engage with PA and sport, but youth does not prefer it as the first reason because they evaluate the health with their physical appearance with $33.08 \%$ and the "for fun" with $35.87 \%$. THG high-school students have evaluated "health" as the main reasons with $8 \%$ and "fun" and Physical appearance". The other schools have a lot of differences in the other alternative. PN School has evaluated "health" with $4.70 \%$ but the other reasons are very low. The differences between $B \& G$ and between schools has naturally some point in common for 3 main alternative "fun" Physical appearance and health but MC G with $10.70 \%$, TH with 9.39 , have evaluated health as the fist reason but the other 4 school PAR with 3.51 , QS with $9.88 \%$, PN with $6.02 \%$ and THG with $13.55 \%$ have selected "fun" as the first reason. In the other side other 4 school for B QS with $7.59 \%$, PN with $6.49 \%$, MC with $18.49 \%$ and GJK with $3.29 \%$ have selected "to improve your physical appearance" alternative (Table 5).

Question 6. From the following reasons, what is currently preventing you the most from practicing sport more regularly?
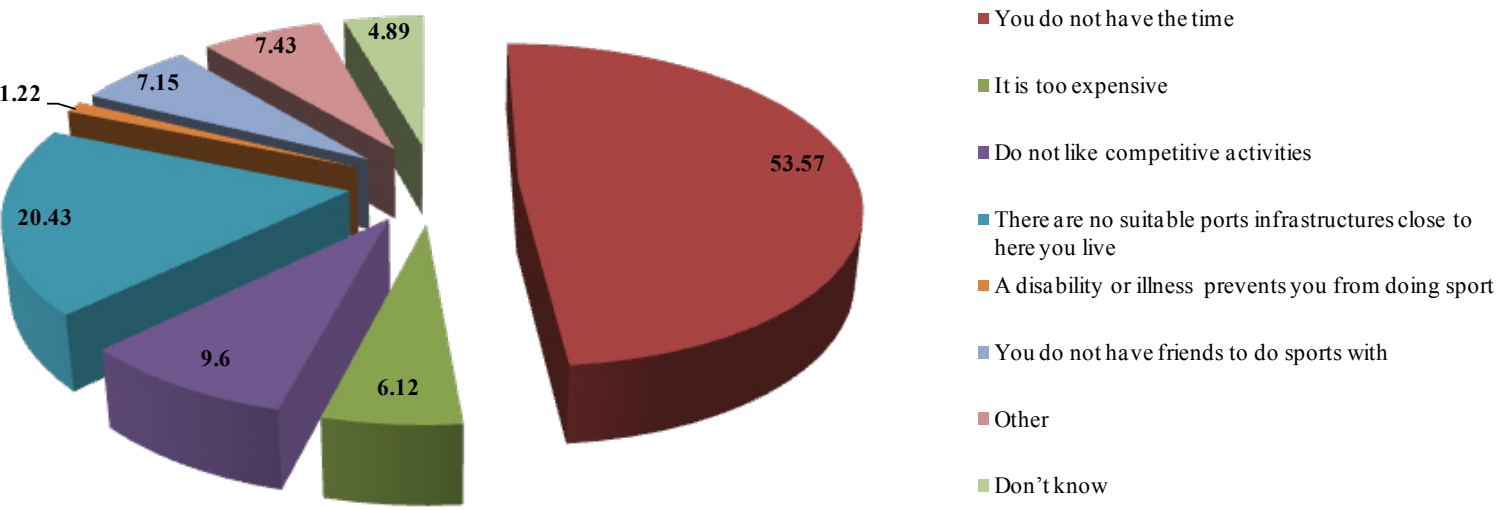

Figure 12. (Question 6) Total results (B \& G).

In general students rapport that they "don't have time" to engage with PA and sport (53.57\%). Also the lack of "infrastructure" with $20.43 \%$, is another factor influencing in their engagement in PA and sport. Following the alternative "do not like competitive activities" comes third with $9.6 \%$. Fourth alternative comes, "is to expensive", with $6.12 \%$ (Figure 12). 
Gender differences

\section{Boys \%}

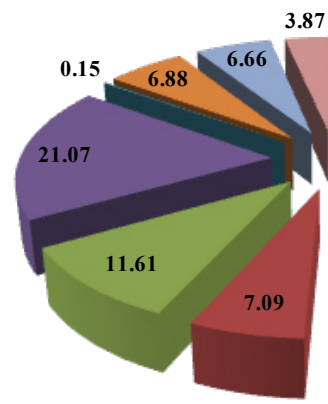

- You do not have the time

- It is too expensive

- Do not like competitive activities

- There are no suitable ports infrastructures close to here you live

- A disability or illness prevents you from doing sport

You do not have friends to do sports with

- Other

- Don'tknow

Figure 13. (Question 6) Total results boys (\%).

\section{Girls \%}
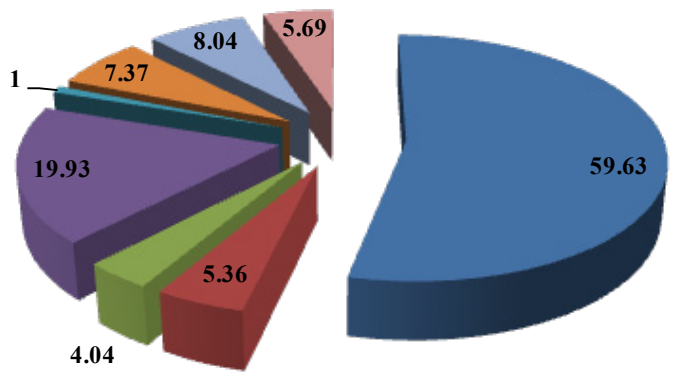

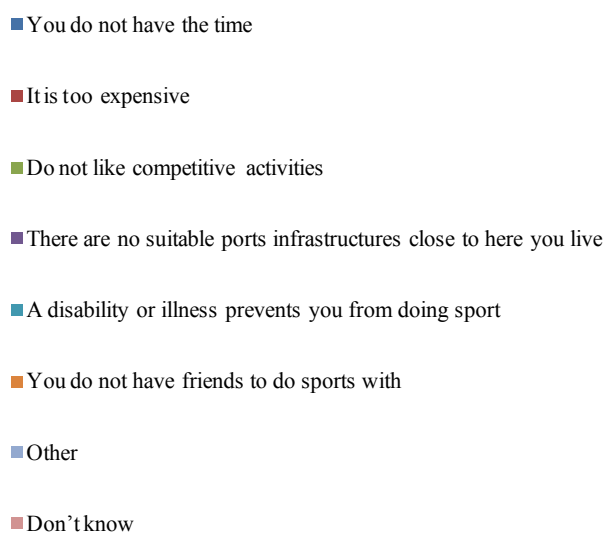

Figure 14. (Question 6) Total results girls (\%).

B and G report that "don't have time" to engage with PA and sport (B 58.8\% \& G 59.63\%). Lack of "infrastructure" is another factor influencing in their engagement in PA and sport (B 21.07 \& G 19.93\%) (Figure 13 and 14). In the alternative "do not like competitive activities" results show $B$ with $11.61 \%$ and $G$ with $4.04 \%$ and the alternative is "is to expensive" results show B with $7.09 \%$ and $G$ with $5.36 \%$. A disability or illness prevents you from doing sport" that they are related with the lack of organized sport programs despite the school sport program. Naturally the alternative "is too expensive" with B with $7.09 \%$ and $\mathrm{G}$ with $5.36 \%$ is related with their financial dependence from their parents. 
Table 6. (Question 6) Total schools result.

\begin{tabular}{rrccccc}
\hline Possible responses PAR & QS & PN & THG & MÇ & GJK \\
\hline You do not have the time 0.37 & 8.9 & 6.37 & 11.48 & 18.92 & 2.68 \\
It is too expensive 0.47 & 0.75 & 0.98 & 1.31 & 1.91 & 1.31 \\
Do not like competitive activities 0.56 & 0.75 & 1.97 & 1.31 & 3.58 & 1.41 \\
There are no suitable ports infrastructures close to here you live 0.47 & 5.89 & 5.36 & 2.07 & 3.1 & 3.58 \\
A disability or illness prevents you from doing sport 0.09 & 0.09 & 0.09 & 0.37 & 0.37 & 0.18 \\
You do not have friends to do sports with 0.98 & 1.5 & 0.56 & 1.12 & 2.54 & 0.47 \\
Other 0.98 & 0.47 & 0.75 & 2.35 & 1.69 & 1.03 \\
Don't know 0.28 & 0.47 & 1.6 & 0.47 & 0.91 & 1.03 \\
\hline
\end{tabular}

Also results report that lack of time is one of the main reasons influencing their participation with PA and sport. G of PAR high-school with $4.39 \%$, QS with $9.88 \%$, THG with 14.72 and MC with $22.17 \%$ have selected the alternative "do not have free time. In the other side B of all schools PAR with $6.02 \%$, QS with 7.74 , PN with $6.45 \%$ THG, with $7.25 \%$, MÇ with 14.83 and GJK with $3.44 \%$ have reported the same reason (Table 6).

\section{DISCUSSION}

The findings of the study suggest that more studies focused on high-school students are necessary to be developed, especially focused on the needs of this group and also intervention studies are necessary in order to evaluate which is the most proper PA program for each individual school. Research has shown that the school and the sport environment is an importance cause for the decrease of students' perceived athletic competence (Digelidis \& Papaioannou, 1999; National Association for Sport \& Physical Education, 2003). Physical education programs that develop students' belief in their own ability and that encourage participation could influence their long term exercise behaviors and the amount of enjoyment they derive from that participation (Tannehill \& Zakrajsek, 1993). In another study, it was found that males like physical activity more than females do, claiming that physical activity enables them to have a healthier lifestyle.

\section{CONCLUSIONS}

More research studies focused on high-school students, where individual, social, and physical environmental factors should be taken into consideration in order to clarify the needs and the proper physical exercise programs for this group category. Sport policies and sport health related benefits needs to be promoted in order that all interested age groups (in this case high-school Students) will understand the sport related health benefits. Also is very important that Local and National sport authorities should create, promote and support more PA and sport projects when people should be encouraged to engage more into them. Physical education curriculum and programs must be designed to reflect the needs and interests of all children to ensure that both boys and girls have opportunities to be successful in motor performance and thus develop a belief in their own ability. 


\section{REFERENCES}

1. ABDULLAH NA \& OMAR-FAUZEE MS. Senaman dan kesejahteraan diri [Exercise and selfwelness]. In Mohd. Sofian Bin Omar Fauzee. (Ed.). Psikologi sukan: Konsep dalam latihan dan pengajaran sukan [Sports Psychology: The concepts of teaching and sports training] Kuala Lumpur: Utusan Publication. 2002; 2-19.

2. ANDERSEN LB, HARRO M, SARDINHA LB, FROBERG K, EKELUND U, BRAGE $S$, \& ANDERSSEN SA. Physical activity and clustered cardiovascular risk in children: a cross-sectional study (The European Youth Heart Study). Lancet. 2006; 368:299-304.

3. AZZARITO L \& SOLOMON MA. A reconceptualization of physical education: the intersection of gender/race/social class. Sport, Education and Society. 2005; 10(1):25-47.

4. BIDDLE S, CAVILLI N, \& SALLIS J. Policy framework for young people and health enhancing physical activity. In: S. Biddle, J. Sallis, \& N. Cavill (Eds.), Young and Active? Young people and health enhancing physical activity - evidence and implications. London: Health Education Authority. 1998; 3-16.

5. CARROL B \& LOUMIDIS J. Children's perceived competence and enjoyment in physical education and physical activity outside school. European Physical Education Review. 2001; 7:24-43.

6. CHRISTODOULIDIS T, PAPAIOANNOU A, \& DIGELDIDIS N. Motivational climate and attitudes toward exercise in Greek senior high school: A year-long intervention. European Journal of Sport Science. 2001; 1(4):2-11.

7. DIGELIDIS N, \& PAPAIOANNOU A. Age - group differences in intrinsic motivation, goal orientations and perceived of athletic competence, physical appearance and motivational climate in Greek physical education. Scandinavian Journal of Medicine and Science in Sports. 1999; 9:375380.

8. DUNCAN MJ, AL-NAKKEB Y, NEVILL A, \& JONES M. Body image and physical activity in British secondary school children. European Physical Education Review. 2004; 10(3):243-260.

9. FOX K. Motivating children for physical activity: Towards a healthier future. Journal of Physical Education, Recreation, and Dance. 1991; 62(7):34-38.

10. FLINTOFF A. Targeting Mr average: participation, gender equity and school sport partnerships. Sport, Education and Society. 2008; 13:393-411.

11. GARRET R. Negotiating a physical identity: girls, bodies and physical education. Sport, Education and Society. 2004; 9(2):223-237.

12. KAMTSIOS S, DIGELIDIS N. Physical activity levels, exercise attitudes, self-perceptions and BMI type of 12-years children. Journal of Child Health Care. 2008; 12(3):228-237.

13. MALINA R. Adherence to physical activity from childhood to adulthood: A perspective from tracking studies. Quest. 2001; 53:346-355.

14. MARTENS R. Turning kids on to physical activity for a lifetime. Quest. 1996; 48:303-310.

15. NATIONAL ASSOCIATION FOR SPORT \& PHYSICAL EDUCAITON. Adulttteens attitudes towards physical activity and physical education. Publication of the United States Sports Academy; 2003.

16. SALLIS JF, PROCHASKA JJ, \& TAYLOR WC. A review of correlates of physical activity of children and adolescents. Medicine and Science in Sports and Exercise. 2000; 32:963-975.

17. STRONG WB, MALINA RM, BLIMKIE CJR, DANIELS SR, DISHMAN RK, GUTIN B, et al. Evidence based physical activity for school-age youth. The Journal of Pediatrics. 2005; 146:732737.

18. SCANLAN TK \& SIMONS JP. The construct of sport enjoyment. In: Motivation in sport and exercise. G.C. Roberts (Ed.). Champaign, IL: Human Kinetics .1992; 199-215. 
19. SOINI M. Motivaatioilmaston yhteys aktiivisuuteen ja viihtymiseen liikuntatunneilla (The association between motivational climate, physical activity, and enjoyment in Finnish physical education). Studies in Sport, Physical Education and Health. 2006; 120.

20. SILVERMAN S \& SUBRAMANIAM PR. Student attitude toward physical education and physical activity: A review of measurement issues and outcomes. Journal of Teaching in Physical Education. 1999; 19:97-125.

21. TANNEHILL D \& ZAKRAJSEK D. Student attitudes towards physical education: A multicultural study. Journal of Teaching in Physical Education. 1993; 13:78-84.

22. TELAMA R \& YANG X. Decline of physical activity from youth to young adulthood in Finland. Medicine and Science in Sports Exercise. 2000; 9:1617-1622.

23. VAN WERSCH A, TREW K, \& TURNER I. Post-primary school pupils' interest in physical education: Age and gender differences. British Journal of Educational Psychology. 1992; 62:56-72. 